\title{
18 The Art of Food Rituals as a Practice in Sympoiethics
}

\author{
Miche Fabre Lewin and Flora Gathorne-Hardy \\ Coventry University
}

\section{CONTENTS}

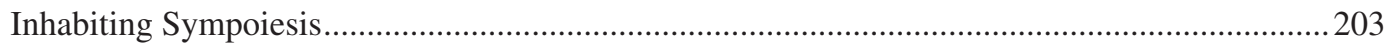

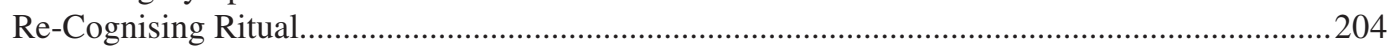

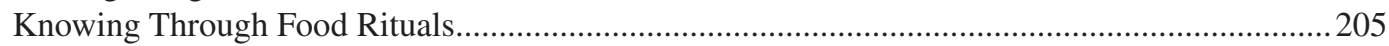

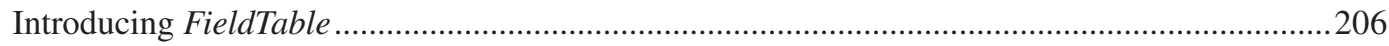

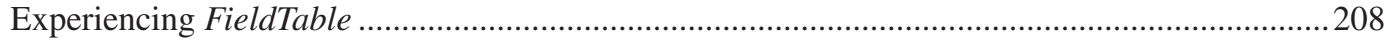

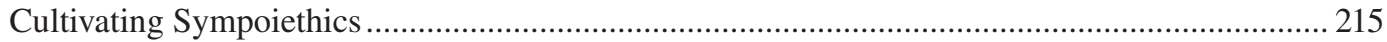

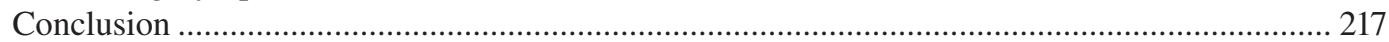

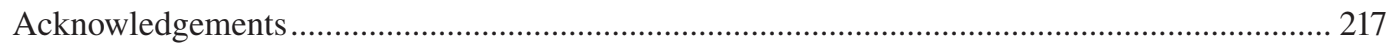

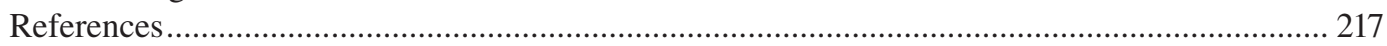

\section{INHABITING SYMPOIESIS}

In a humble gesture of touching the soil with the fingers of his right hand, Buddha shows his allegiance to the Earth as his authority, reminding us that our human bodies are in a vital and everyday relationship with the body of the planet. His gesture is in resistance to Mara's temptations to draw him into the conditioned existence of separation, delusion and desire and an expression of his understanding that the Earth is his witness (Thomas, 2000). This sacred image of the Buddha with his own body in connection with the Earth grounds ethical conduct as part of whole-bodied consciousness. Our humanity flourishes as part of the animate and interconnected systems of the living Earth where we are in an on-going entanglement with each other and the matter of all existence (Abram, 2010; Barad, 2012; Gablik, 1992; Haraway, 2016; Ho, 2008; Laszlo, 1996; Weiwei, 2020). Addressing and engaging in social and environmental justice is an invitation for us to notice and practice our humanhood as an embodied and physical experience in relationship with the other-than-human world (Roszak 1977). Traditional knowledge systems and ancient spiritual wisdoms recognise this embodied, participatory worldview and the unifying consciousness where, in kinship with Gaia, 'we participate in the intimacy of all things with each other' (Berry, 2006: 137). This is a poetic ecology that enables our fragmented selves 'to find our place in the grand whole again' (Weber, 2019: 3) (Figure 18.1).

For, while we as living creatures are bounded as independent, autopoietic organisms with the capacity to self-reproduce and cohere living processes (Maturana and Varela, 1980), we also co-exist within the interdependence of ecosystems with synergistic behaviour of 'linkages, feedback, cooperation' (Dempster, 2000: 4). Complementing the concept of autopoiesis, biologist Beth Dempster conceived the term 'sympoiesis' to describe the inherently interactive and cooperative behaviour of living systems sym meaning with, or together, and poiesis to make, create or produce (ibid). In adopting a sympoietic sensibility, the separation between nature and culture dissolves and we as humans become active, sensing organisms within the dynamic flow of a non-heirarchical and interconnected cosmology.

Sympoiesis diffracts with current feminist, decolonial and environmental narratives of power by re-orienting us towards a worldview based on life-affirming encounters between our personhood, each other and the habitats of the animist world. Donna Haraway speaks of naturecultural 


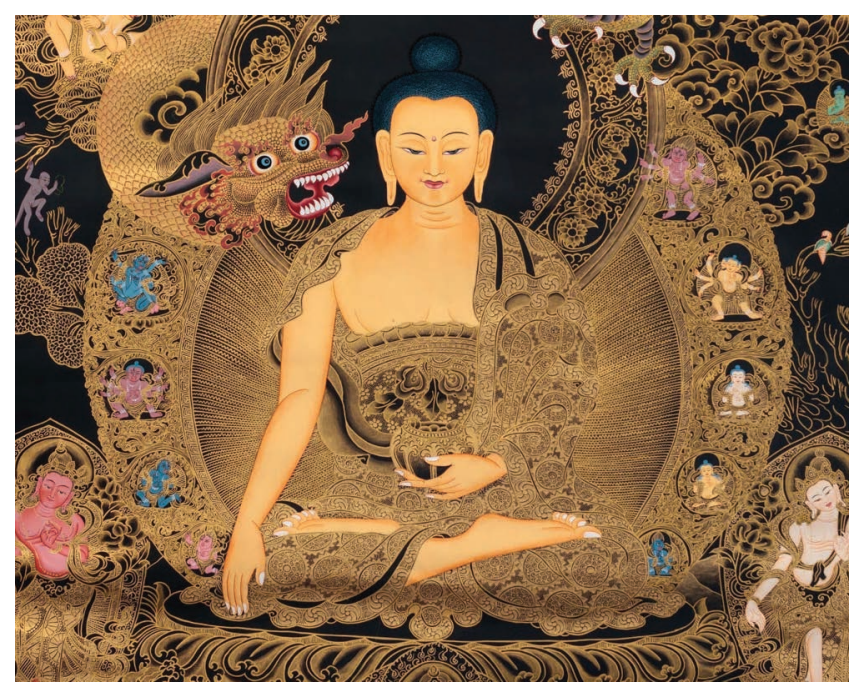

FIGURE 18.1 Buddha resisting the temptation of Mara. (Image credit: Exotic India Art.)

being and becoming-with to describe this interconnectedness as a mode of being where "nothing makes itself', rather, 'we are worlding-with, in company' (Haraway, 2017: M25). Maria Puig de la Bellacasa reflects on such naturecultural thinking as emerging through 'knots of relations involving humans, nonhumans, and physical entanglements of matter and meaning' (Puig de la Bellacasa, 2017: 141). Addressing the feelingful body as one with the thinking mind, Weber calls for a position of 'enlivenment' where thought and practical action are reanimated with 'life' and 'aliveness'(Weber, 2019: 11). Minna Salami presents 'exousiance' as 'the catalytic power of being and becoming together with everything else that is being and becoming' (Salami, 2020: 1-2). This power of aliveness is what we as humans share with every living entity, a power which arises from source and has the capacity for integrating social change with ecological restoration.

Sympoiesis interweaves the concept of the convivial, which also invokes the expression of interrelationship with its Latin roots of con 'with' and vivere 'to live'. The convivial guides us towards an embodied ethics where 'we creatively and autonomously live, work and relate to each other in the everyday life' (Ballantyne-Brodie, 2018: 1034-1035). A convivial praxis attends to the larger whole by animating inclusive cultural spaces where we all, human and other-than-human, can experience, recover and respond within a continuous intra-acting with the matter and life processes of the world. Within forest ecology, refugia are spaces for habitat restoration through the revival of ecological and agricultural biodiversity (Barthel et al., 2013). Inspired by the work of Anna Tsing (Tsing et al., 2017), Haraway reframes bio-cultural refugia as places of naturecultural resurgence for the revival and flourishing of ways of living that have been forgotten, denied or subjugated (Haraway, 2015). For us to become more wholly human, we are called into a radical conviviality of co-existence and responsiveness with each other and the other-than-human world.

\section{RE-COGNISING RITUAL}

Ritual has the potential to manifest bio-cultural refugia as collective gatherings that are inclusive of all inhabitants of a place by creating bounded space and time to explore, open to and cultivate new forms of interrelationship that are non-hierarchical and connecting across differences. Ritual practice has been embedded within the making of naturecultures since the birth of humanity as a cultural form for generative sympoietic interaction (Grimes, 2015; Turner, 1969). Affirming the role of ritual as an ecological and participatory practice of life, Ronald Grimes defines it as 'the basic social act, the fabricator, the device for world-and meaning-making' (Grimes, 2015: 2). As performative acts, 
rituals are spatial and temporal encounters that 'include order, tradition, and prescribed actions but also innovation and creativity, improvisation and randomness' (Grimes, 2015: 3). Rituals enacted for the sacred naturecultural purpose of world-making share an interweaving sequence of three transitions: the separation from ordinary everyday life; the liminal, threshold space of transformative experiences and closure, which embraces the potential reincorporation of the wisdoms and teachings which have occurred during the ritual encounter (Turner, 1969; Van Gennep, 1960).

The innovation of ritual practices as containers to restore deeply experiential ways of knowing within a participatory consciousness is an active recovering of Rta, the Sanskrit roots from which both 'art' and 'ritual' originate. Rta is understood as 'the synergy of materials, forms and processes ... the dynamic movement from which all arises' (Haley, 2016: 46). These ritual practices offer the potential for embodied, emergent and evolutionary forms that are responsiveness to self, other, matter and place. As Victor Turner confirms, the liminal quality inherent in ritual offers the potential to 'generate and store a plurality of alternative models for living ... in the direction of radical change' (Turner, 1985: 33). Echoing Turner, Frederique Appfel-Marglin conveys the essential dynamic role of performing intra-actions or rituals ceremony for 'making a livable common world' (Apffel-Marglin, 2011: 162).

Rituals afford us rigorous and extensive thinking-feeling practices by engaging our bodyminds in the matter, substances and processes of life. As a contemporary ecological arts practice, Touchstones Earth co-evolve and host rituals as refugia for embodied thinking within a sympoietic sensibility that honours the sacred as 'the changing, flowing, thinking/Of the world' (Bateson quoted in Charlton, 2008: xiv). These choreographies in time and space are performative encounters that encourage interaction between feeling and knowing, site and psyche, mind and body, nature and culture and the cycles of past, present and future (Mathews 2003). Within a bounded form, the bodymind experiences being-with oneself, other people, matter and place as a conscious process of regenerative world-making - the 'material engagement in labours to sustain interdependent worlds' (Puig de la Bellacasa, 2017: 198; Ryan et al. 2016). As Clifford Geertz reflects, rituals are spaces where we can come to know how to act because we know how we feel (Geertz, quoted in Grimes 2015: 1). Thus, it is in the making of ritual that we can cultivate and practice a sympoietic and political consciousness that respects our interdependent origins with each other and the Earth (Gablik 1992a). Joanna Macy, in her despair and empowerment sessions, animates healing with ritual work. These rituals become conduits for deepening into our inner emotional life, reaching out to each other and cultivating actions in respect of the other-than-human world of which we are a part (Macy, 1991). In his work with ritual, Malidome Some reflects that participation in a communitas is 'a pre-requisite for true ritual healing, for a sense of belonging that satisfies, and for a rewarding understanding of Spirit' (Some, 1998: 294). As Matthew Fox considers in conversation with Rupert Sheldrake, ritual has its value for a radical cosmology of interconnectedness and forms the basis of morality. Fox writes:

All healthy ritual is an invitation to doing things together, not being spectators watching someone else do something, but inviting people to truly participate with their own bodies, their own images, their own breath and their own visions.

Fox and Sheldrake (1996: 147)

\section{KNOWING THROUGH FOOD RITUALS}

Food decisions impact on all aspects of our lives, every day, every mouthful. Carolyn Steel writes, 'food emerges as something with phenomenal power to transform not just landscapes, but political structures, public spaces, social relationships, cities' (Steel, 2008: 307). Reflecting on the art of Joseph Beuys and his culinary happenings, Lemke writes of 'gastrosophy', a philosophy which reframes the ritual of food-making as an art and aesthetics of everyday life (Lemke, 2007: 53). In the ancient Hindu philosophical scriptures of the Upanishads, the nature of knowledge is explored through the substance and metaphor of food as part of life's interconnected cycles of decay and renewal. The translated extract from Sanskrit is a testimony to how food is a profound medium for 'coming to know': 
First Know Food

From food all things are born.

By food they live,

Toward food the move

And into food they return.

Taittiriya Upanishads

Through the medium of food, naturecultural entwine. Touchstones Earth draw on the power of food as a way of knowing to co-evolve contemporary food rituals within the fields of ecological food cultures, regenerative agroecology and social healing. Central to this ritual practice are embodied encounters with the matter of the living food cycle - the cycle of soil and water care, food growing, food sharing and food composting where food waste is returned back to the soil. Cultivating food rituals as refugia engages the bodymind in enlivening encounters with agricultural methods, culinary traditions and the geographies of food cultures. This extensive and reflexive experience with food provides space and time for participants to sense, imagine and awaken memories, feelings and thoughts (Curtin 1992). They enact threshold containers for remembering forgotten wisdoms, reviving artisanal skills and generating new possibilities in respect of naturecultural living. Such embodied explorations cultivate a politics of participatory consciousness where the bodymind is in a coming to know and a becoming-with the world, in an integrated expression of care as an ethics of the everyday.

Touchstones Earth's rituals as refugia respect, reframe and improvise within an existing lineage of cultural and agricultural food ritual traditions. Within Jewish culture, the ritual table of the Haggadah with its Seder plate recalls the experience of Passover and, through symbolic foods, remembers the significance of the Exodus from Egypt. Agricultural traditions that acknowledge and work through and with the subtle energies of nature include: the Vedic ceremony of the daily fire ritual Agnihotra performed at sunrise and sunset; and Rudolf Steiner's teachings that elaborate the application of biodynamic preparations for soil and plant health in attunement with celestial and diurnal rhythms. Agrarian harvest festivals are celebrated across the world to honour the first fruits of the season with thanksgiving rituals and feasts. These rituals of the table and the field are healing, purifying and restorative as they encourage an awareness and a focus of intention to histories and geographies through spacious, sensuous and sympoietic interactions. They respect the energies of genius loci, the agency of human experience and the regenerative power inherent in plant, animal and mineral - all in a dance with seasonal rhythms, natural elements and the Earth's solar system.

\section{INTRODUCING FIELDTABLE}

The food ritual FieldTable grew from Miche's impulse to create an edible intervention as an embodied agricultural alternative to a Union Carbide advertisement within the 1976 Scientific American journal addressing 'The Future of Agriculture' (Scientific American 1976). The text within the double-page spread reads, 'We are expecting a few extra people for dinner tonight'. The dramatic image is of a long, white-clothed table which curves into the horizon within a ploughed field of barren soil denuded of all plants and biodiversity. At the table, the green velvet chairs are empty. The plates and glasses are empty. Below the image are promises of the power and efficiency of the 'green revolution' to grow more food using artificially synthesised insecticides, gels, crops and plant treatments for the 213,000 'extra people'.

The precursor to FieldTable was conducted in 2006. In collaboration with an organic farmer in Shropshire, UK, Miche hosted an environmental dining experience CloverField Feast in a field of clover grazed by cattle. Here, participants experienced an embodied taste of eating as an agricultural act (Berry, 1993). As part of the ritual, the 12 participants were invited to engage with the question, 'What is food'? A decade later in 2016, the opportunity emerged to manifest FieldTable on a biodynamic farm near Stellenbosch in the Western Cape of South Africa. During Miche's Living Cultures: Kitchen culture meets agriculture Artist Research Residency at the Sustainability Institute she and Flora met a local landowner who gave them a tour of his biodynamic farm in the Lynedoch region. Whilst walking in and with the land, Miche shared her idea of hosting a 
regenerative farm-based food intervention. This notion was greeted with enthusiasm by the farmer and preparations began to curate this edible experience on one of his biodynamic fields.

Addressing and engaging with the personal and political dimensions of oppression through emancipatory practice motivates all of Miche's work in the world. As a woman with Jewish heritage born white into the colonial regime of Rhodesia, Miche recognises and engages with the multiple dynamics of oppression. Aware of how white body supremacy has conferred privilege on her life (Menaken, 2020) she is also tuned into how her human existence entwines within other systemic discriminations which segregate, marginalise and exploit. Her contemporary food rituals arise from a body of work which is committed to intervening in and countering the separation between ourselves, each other and the multisentient communities of our planet. Through creating liberatory conditions for embodied experiences with the living food cycle these convivial encounters prepare a common ground for fostering respectful, inclusive and celebratory relationships.

Given the legacies of apartheid in South Africa and on-going land contestation coupled with food insecurity the invitation to host the food experience FieldTable was politically dynamic. The durational ritual was conceived as a convivial intervention for participants from diverse ethnicities, cultures, ages, classes and genders to gather around a dining table in an unfamiliar context to share different experiences, perspectives, aspirations and vocations. Those at FieldTable included agroecology students and educators, gardeners and farmers, organisational leaders and activists, bakers and chefs, scientists and ecologists, journalists and researchers and artisan food producers. This kinship of people emerged from relationships Miche and Flora had developed during the 3-month artist research residency at the Sustainability Institute. Everyone round the table shared a dedication to agroecological food cultures and regenerative artisanal food production within the region. The event was thus a communitas for the guardianship of soil, water and land as a practice in social, ecological and food justice.

On a September Saturday, the ritual process began with a sensorial travelling experience in a lavender-strewn truck where 22 participants were driven up to a farm track. Continuing on foot, all walked towards a field of grazing cattle where a dining table stood amongst the meadow grasses. As the participants approached FieldTable, they were invited to pause at a shrine, the liminal threshold which signalled the bounded container of a ritual space. The ritual shrine was in honour of the field and its genius loci and was composed of large slice of tree trunk and a selection of matterful objects including a granite touchstone, kalahari salt, a vessel of water, a bowl of soil and a ball of red thread. Miche welcomed people and offered gratitude to the soil and water. Here she invited participants to consider the question 'What are we hungry for'? and to hold this during the food sharing. Once seated, Miche introduced the evolution of FieldTable, and before beginning to eat, participants were asked to pause for a minute of silence in contemplation of their surroundings and with the food on their plate. The mainly plant-based menu of dishes was hand-prepared and cooked using culinary artisanal traditions to enhance the nutritional value. All the produce was sourced and donated from the gardens and farms of local growers who sat around the table. The simplicity of fare included the fresh, the fermented, the raw and the cooked, all composed from the season's local harvests. Sourdough breads from heritage grains were specially baked in woodfire as small baguettes for sharing between two as a gesture of companionship. Seeking to amplify the vitality of the food, to give it voice and allow it to reveal its own nature, the food on the plate displayed a vibrant composition of natural colour, form and texture - food to awaken the senses.

As part of the ritual dining experience, some of the participants stood up to share their passion for their culinary, artisanal and agricultural practices, thereby stimulating the spontaneous reflections and stories of others. Once the food was eaten, leftovers from the plates were collected into bokashi bins to activate a fermentation process that enables foodwaste to become natural fertiliser for the land. The final phase of FieldTable opened a space for self-reflexivity where participants were asked to respond in writing with the question 'How has your hunger been satisfied'? This was followed by closure through exchanges of thanks and farewells (Figure 18.2).

As a durational food ritual, FieldTable was a provocation for the bodymind, enlivening people's capacities to come to know through the senses, the imagination, emotion, intuition and 


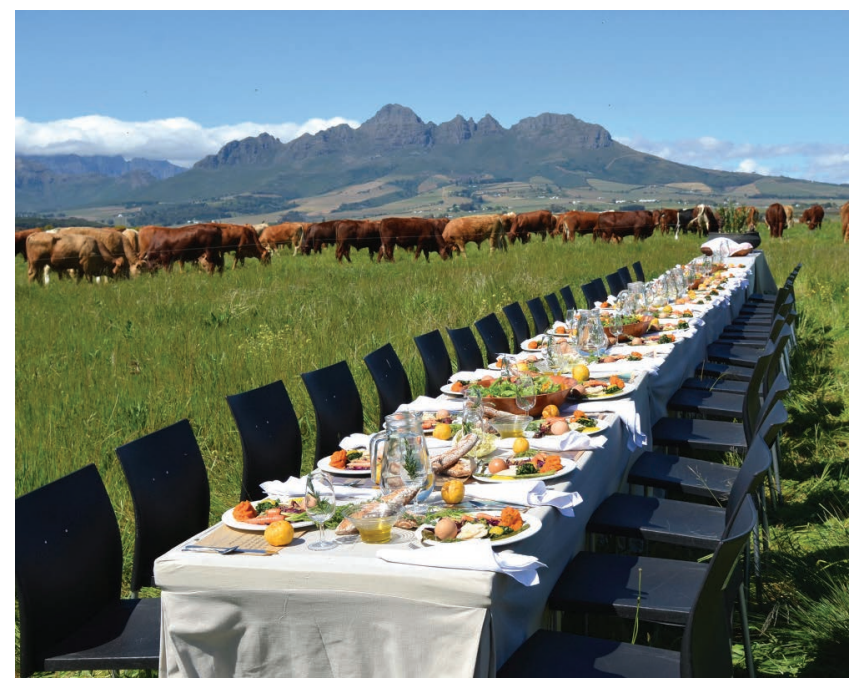

FIGURE 18.2 FieldTable prepared for participant diners. (Image credit: Eva van Niekerk.)

memory in direct contact with the geography and the matter of food. The co-creation of such bio-cultural refugia as a ritual, situated in an agricultural field on biodynamic land, offered the opportunity to know food and to be-with food while experiencing its source and the place of its origin, the living soil. As well as being a thanksgiving ritual in celebration of regenerative and biodynamically grown food of the land, FieldTable sought to be a sympoietic manifestation of convivial life as an 'autonomous and creative intercourse among persons, and the intercourse of the persons with their environment' (Illich, 2001: 86). What follows is a photo-montage of the encounters that unfolded during FieldTable for the reader to pause and feel into, muse on and dwell-with (Figure 18.3-18.16).

\section{EXPERIENCING FIELDTABLE}

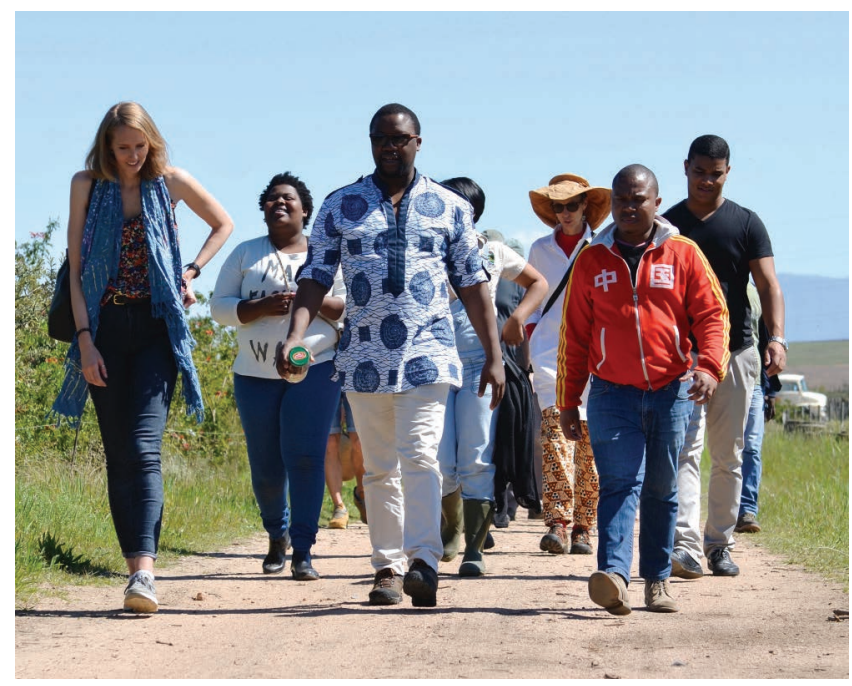

FIGURE 18.3 Participants walking up the farm track to the entrance of the field. (Image credit: Eva van Niekerk.) 


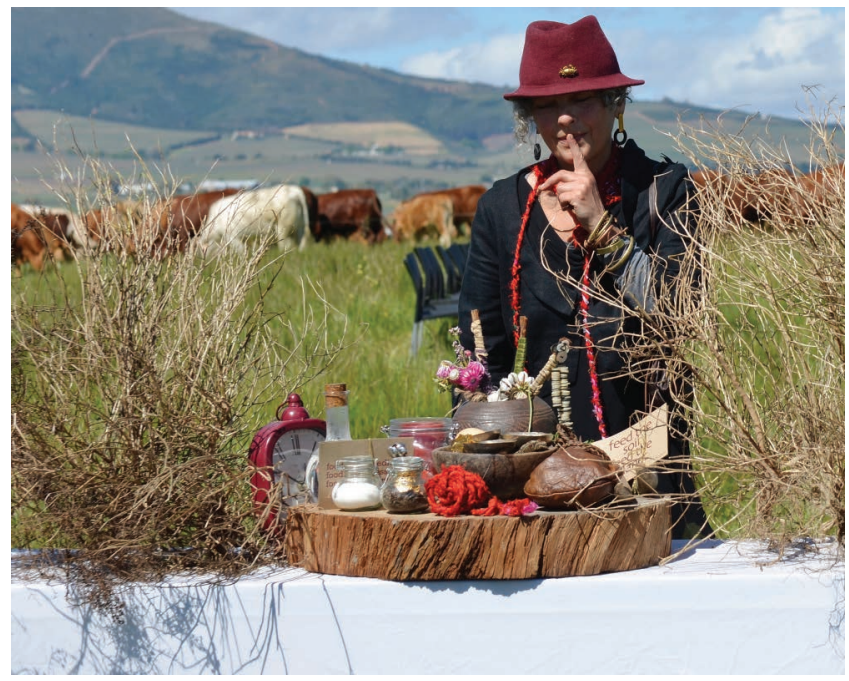

FIGURE 18.4 The field shrine to FieldTable. (Image credit: Eva van Niekerk.)

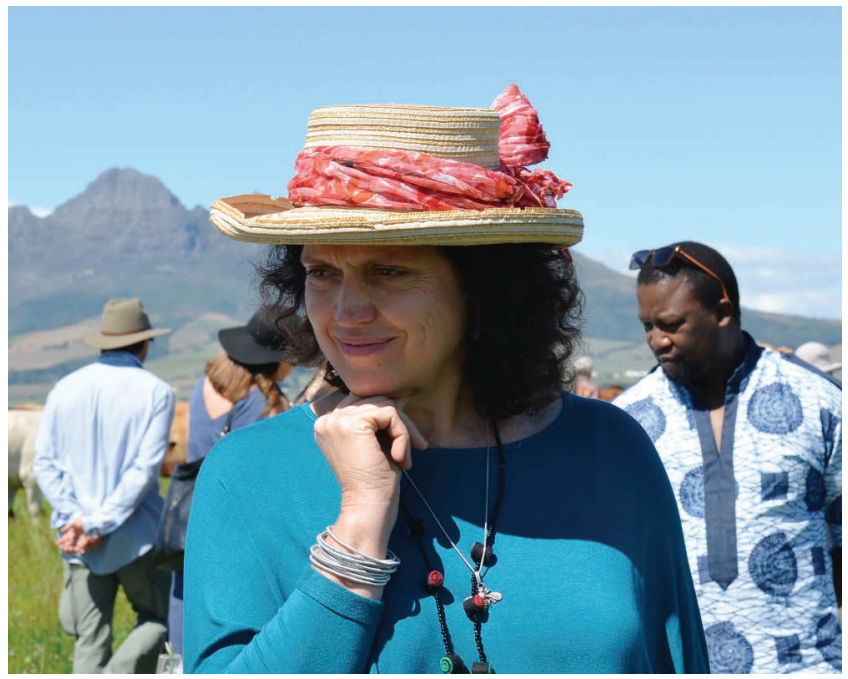

FIGURE 18.5 Being in silence to encounter the genius loci, the grazing cattle and the table of food. (Image credit: Eva van Niekerk.) 


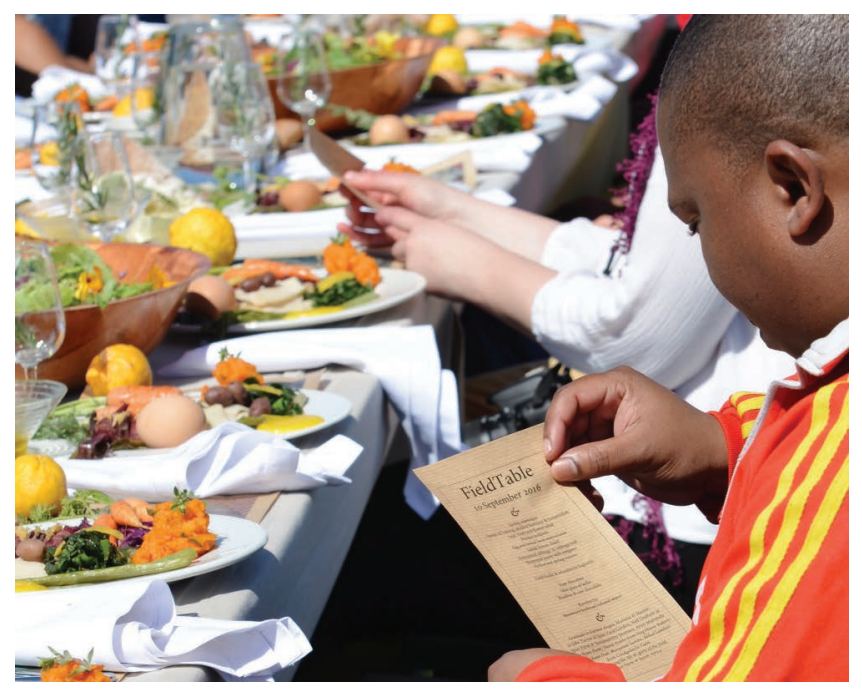

FIGURE 18.6 Reading FieldTable menu of dishes from the season's bounty. (Image credit: Eva van Niekerk.)

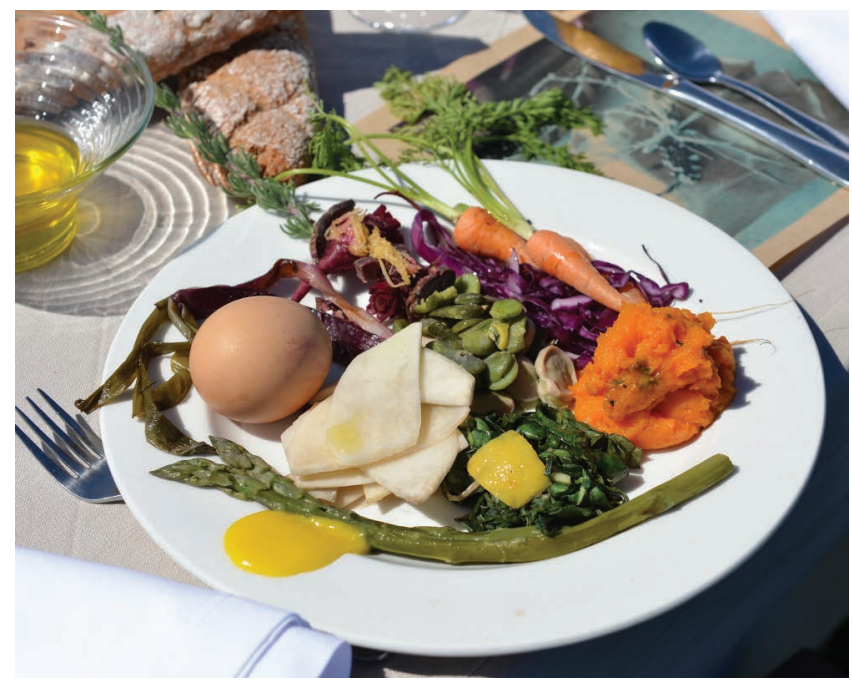

FIGURE 18.7 A plate of locally and naturally grown 'bare awakening food' composed of: poached asparagus; brochettes of biltong, pickled beetroot and horseradish paste; marinated kohlrabi; broad beans with freshly made mayonnaise; salted lemon chard; fermented cabbage; butternut squash puree with oregano; grilled red spring onions; raw whole carrot and boiled egg in shell. (Image credit: Eva van Niekerk.) 


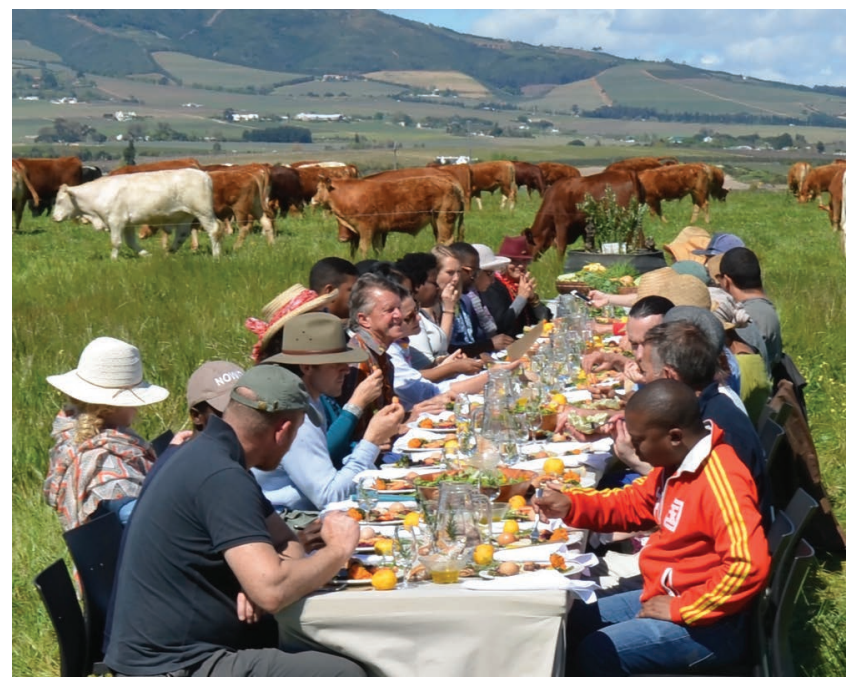

FIGURE 18.8 Participants conversing at FieldTable. (Image credit: Eva van Niekerk.)

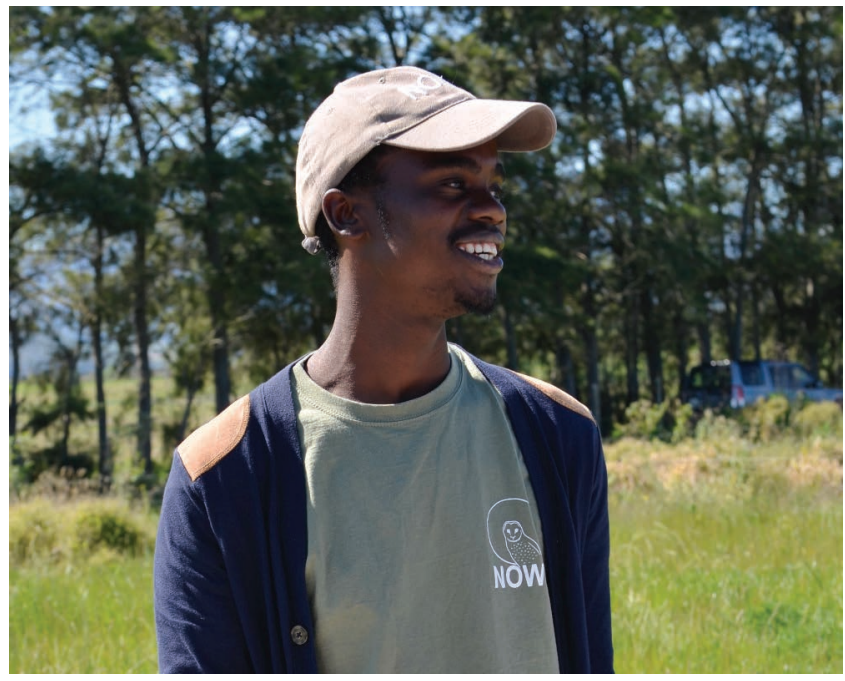

FIGURE 18.9 A young farmer sharing his passions and aspirations for change. (Image credit: Eva van Niekerk.) 


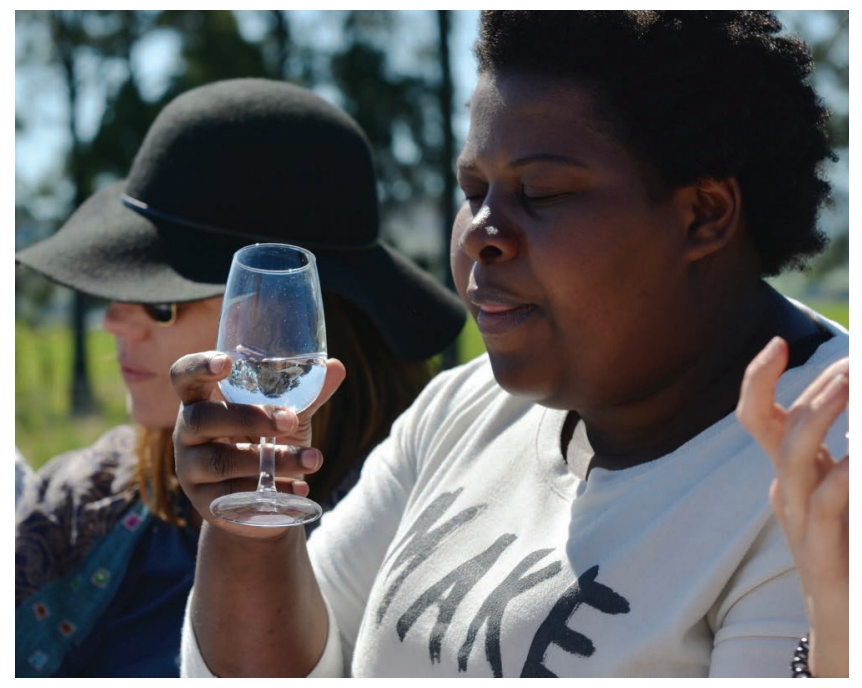

FIGURE 18.10 Tasting rosemary-infused water. (Image credit: Eva van Niekerk.)

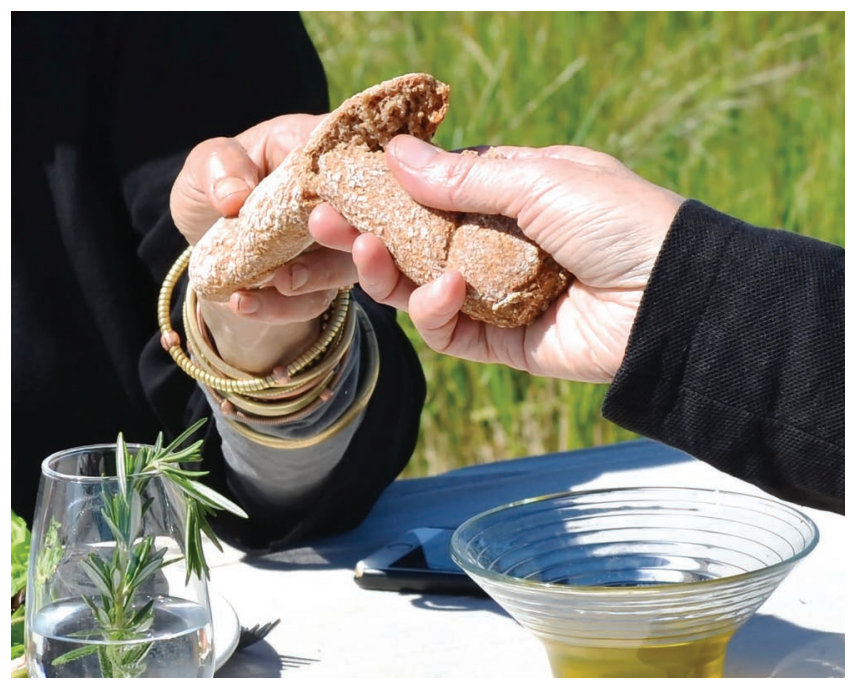

FIGURE 18.11 Breaking bread as a gesture of companionship. (Image credit: Eva van Niekerk.) 


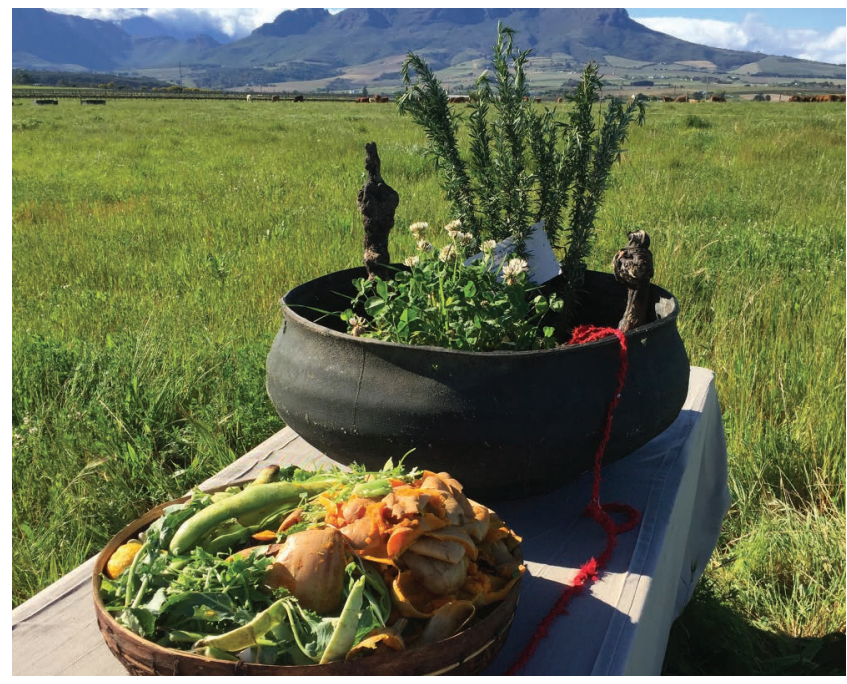

FIGURE 18.12 Soil Shrine making visible examples of natural methods for increasing soil fertility through composting foodwaste and growing clover as a nitrogen-fixing plant. The sprigs of rosemary call us into remembrance. (Image credit: Eva van Niekerk.)

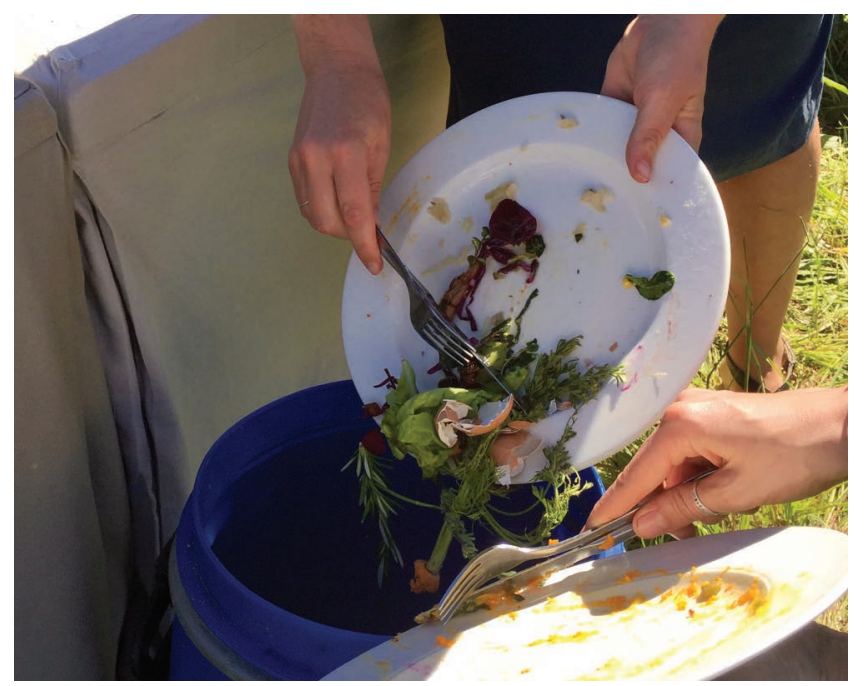

FIGURE 18.13 Leftover food emptied into a bokashi bin. This Japanese fermentation method prepares foodwaste to become a natural fertiliser for soil regeneration. (Image credit: Eva van Niekerk.) 


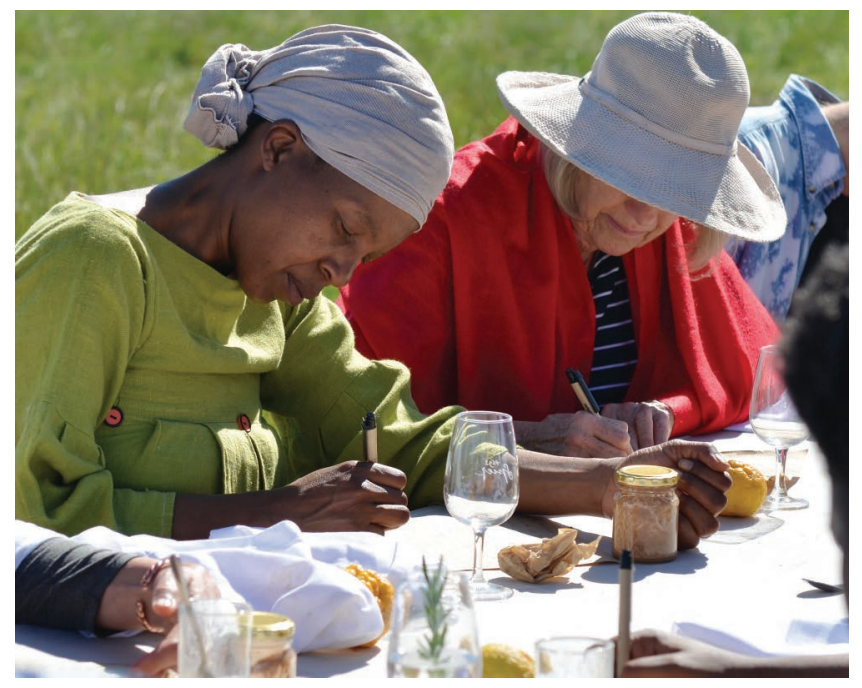

FIGURE 18.14 At the end of the meal, participants write about their experiences of FieldTable and reflect on how their hunger has been satisfied. (Image credit: Eva van Niekerk.)

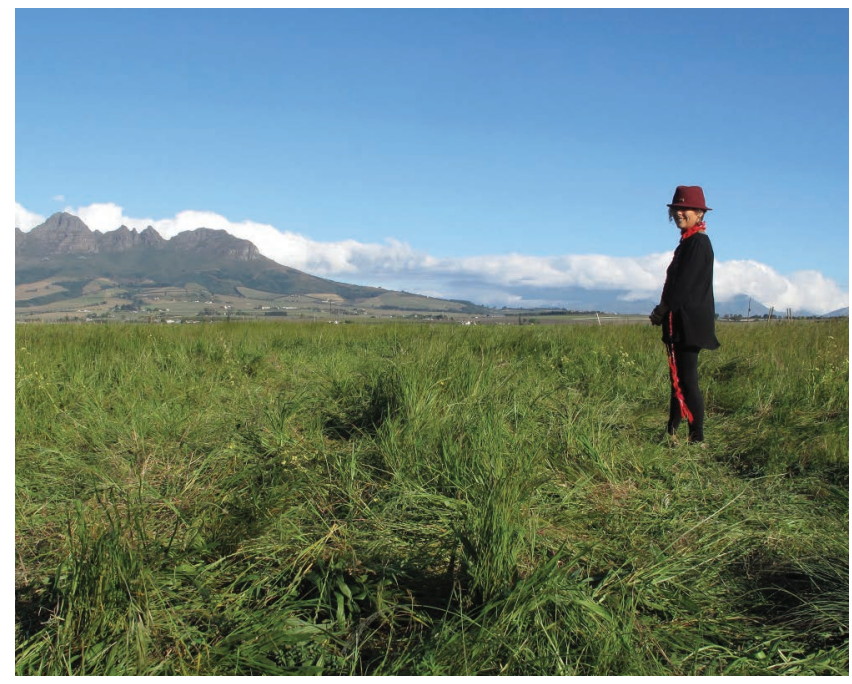

FIGURE 18.15 FieldTable was set up and completed in a day. (Image credit: Touchstones.) 


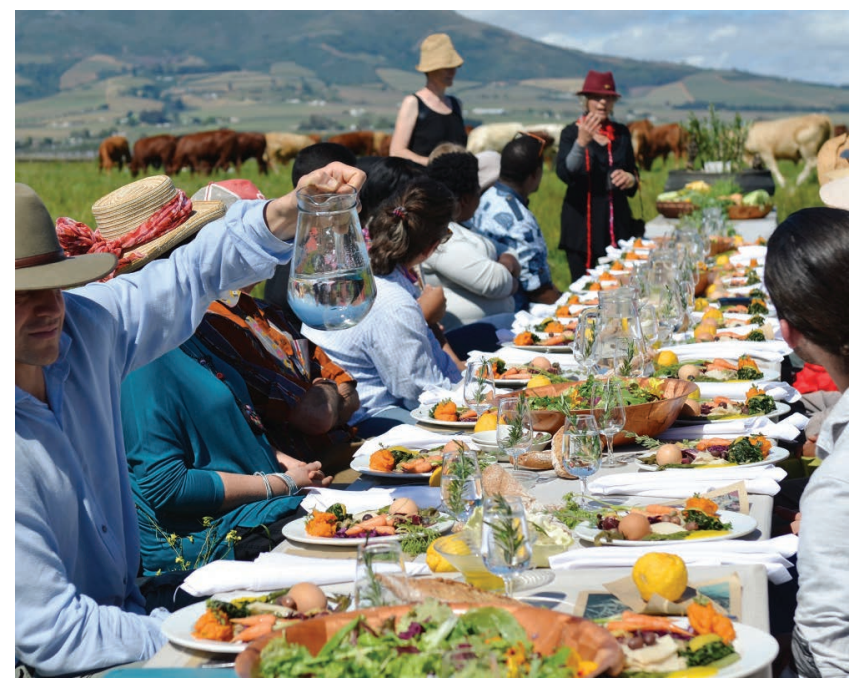

FIGURE 18.16 FieldTable manifests in 2016 as a convivial, local and agroecological narrative to counter the 1976 Union Carbide advert promising synthetic and genetically modified solutions to world hunger. (Image credit: Eva van Niekerk.)

\section{CULTIVATING SYMPOIETHICS}

The food ritual FieldTable responds to Merleau-Ponty's call to artists to 'awaken the experiences which will make the idea take root in the consciousness of others' (Merleau-Ponty, 1945: 8). As a ritual and an edible intervention, FieldTable emerged through relationships between people, matter and the habitats of place. By making visible the abundance and natural fertility of regenerative farming methods through its local harvests of colourful, seasonal produce, and the health of well-reared animals, FieldTable was a space for awakening, inhabiting and re-imagining agroecological futures for the region. As noted above, during the ritual, two questions were asked: at the start of the meal, 'What are you hungry for'? and, at the end, 'How has your hunger been satisfied'? Here follows a selection of participants' responses which shares the diversity of perspectives from women and men of different occupations, ages, cultural heritages and ethnic communities.

The return of the sacred to the table has created time, space

and thinking partners to look at this hunger,

to imagine its voice, its sounds, its texture, its feeling and

find out how to hear it, how to respond to it.

Understanding what my belly inherently needs and wants

to be fully nourished - re-awakening intuition.

I am starving for revolution to our food systems. Starving to see farmers doing away with the systems that harm the mother earth. I want food to be accessible to everyone because food is life.

This is my love for life, my sanctuary, my home.

A sense of freedom, a chance to engage.

A society where diversity is treasured, where food is not wasted;

where Nature becomes and is the most revered

or 'desirable' thing, asset, goal; where food and conversation serve

to respect the farmer, the cook, the soil, and ourselves.

I am searching for beauty ... a new beauty.

A beauty that emerges when time is taken to appreciate and experience

and rediscover what feeds our soul and what we need to do

in order to build resilience to the true challenges of today.

You are re-igniting culture and coming back to what it means to be community ... community along the lines of land and food. 
Under culture you get ritual and agriculture,

it felt literally like what it means to be going back to being human

I hunger to be part of a community that holds at the centre,

so it can hold me, remind me when I get lost in my 'busy-ness',

when I forget about the sacred ... be present

where I can hold this space for other beings, all beings.

Deep changes are, more often than not, slow gradual processes that seem so natural that we hardly notice they are even happening, like the cultural changes taking place beneath the soil, in our guts, and at our tables. I'm hungry for change.

I understand collaboration of life-giving and not life-taking.

The creation of living community in that time and space

helped create a collective mindset to preserve

and create energy that is positive.

Let's go to the townships with this. Because in the townships, we do get to reach people who are practicing organic gardening,

who are using indigenous knowledge to produce.

These reflections from participants document how FieldTable enlivened ways of coming to know through the interrelationship between themselves and the animate matter of life. Within the liminal space of this food ritual as refugia, our human capacity for naturecultural thinking and being-with was enlivened through personal and collective intra-actions with food, artefacts and substances. Their words speak of a longing for more sensuous experiences, for expansive conversations and for regenerative cultural and agricultural practices that foster life-giving interconnectedness between the personal body, the collective body and the body of land. In an exchange with Flora, Miche reflects on the significance of naturecultural rituals within agriculture and explores how FieldTable contributes to such a recovery of the 'cultural evolutionary potential' of ritual (Turner, 1985: 165):

For us humans to be discovering what it means to be truly here is to reconnect with embodied knowing. Being in a continuous relationship with the matter and processes of life is what makes us natureculture creatures: our lifeblood, our life capacity and our consciousness comes from continuous interaction and relationships through our bodies with the dynamic flow of the cosmos. Being in touch with, noticing more, with spaciousness and focus, is what ritual allows, a space and time for attuning and attending through our bodyminds with the living processes of the Earth. It also gives a great sense of joy to be in a ritual that is respecting the self and the collective within the naturalcultural. Ritual connects us to the life force.

Conversation Exchange between Miche and Flora (5 June 2020).

FieldTable offered a taste of the catalytic power of the life force of exousiance which Salami identifies as a stimulus of energy and will for change. FieldTable was a threshold space, a naturecultural refugium for people to experience their bodyminds, within communitas, as an instrument of participatory and political consciousness in a relationship with the biodiversity of the land. Encounters with each other and the matter of food within this contemporary ritual form generated new thoughts, openings and actions. The initiatives emerging from FieldTable were wide-ranging and continue to unfold, and include: the commission of a large-scale FieldTable artwork for the farm office; the impulse to create the infrastructure for food sharing with staff at the farm where FieldTable took place; the Sustainability Institute linking to a local cooperative food hub and creating food citizen lunches from the food garden and a follow up Agroecology Ndaba forum exploring agroecological training with educators, students farmers, food activists and policymakers. Daryl Jacobs, Deputy Director at Elsenburg Agricultural Training College reflected on the role of food and soil rituals as offering transformative experiences of nature-based farming for young trainee farmers:

What I value and treasure is the real deepened transformation ... your healing of soul and soil. It emphasises that we are part of one system, but unless we transform our thoughts processes from deep within, from the soul, it will be superficial. 
Naturecultural food rituals as refugia are a reminder of how our human response-abilities are intimately entangled with interdependence. This relational way of knowing is embraced by the concept of 'sympoiethics' where our artful bodyminds become the divining instrument for enculturing art and ethics as a practice of life. Miche expands on her concept of 'sympoiethics' in a conversation with Flora;

Human existence is lived through and within a dynamic nexus of living processes. Human oppression is intertwined with the degradation of the Earth. Authentic human flourishing emerges through restoring an ethos where the dignity of selfhood is interwoven with a respect for place and care for our sentient, multispecies Earth. A sympoiethics combines sympoieisis with ethics. Ethics, rooted in ethos, defines dwelling places where we come to know together through place-based relationships

Exchange between Miche and Flora (April 2020)

\section{CONCLUSION}

The Buddha's enlightenment under the Bodhi tree symbolises how our human existence flourishes through our care for each other and the Earth. Consciousness and knowing arise through embodied encounters with naturecultures which call for us to notice and value the body's multiple intelligences and the subtle energies which surround us (Fabre Lewin, 2012). A sympoiethics awakens us, with and through our bodyminds, to emancipatory practices and reciprocal responsibilities for living, loving, thinking, being and acting in ways that are equitable and responsive to our co-dependent existence (Fabre Lewin, 2019). Naturecultural food rituals create the conditions to enliven our ecological selfhood through an authentic relationship with food - experiential rituals as refugia which are practices for transitioning towards a participatory world view and a politics of consciousness. It is within this nexus that food is a changemaker with its role in reorienting the matter of our thinking, reshaping our landscapes and reconfiguring our responseabilities as humans within the geography of our planet. In co-creating naturecultural rituals, we are reviving thinking-feeling practices that respect each other's embodied knowing, attend to the voice of nature and cultivate a sympoiethics that draws its life-affirming power from our caring for and becoming-with the living Earth.

\section{ACKNOWLEDGEMENTS}

Gratitude to all beings who have been in generous collaboration with, contribution to and enlivening of the evolution and manifestation of FieldTable.

\section{REFERENCES}

Abram, D. (2010) Becoming Animal: An Earthly Cosmology. New York: Vintage Books.

Apffel-Marglin, F. (2011) Subversive Spiritualities: How Rituals Enact the World. Oxford: Oxford University Press.

Ballantyne-Brodie, E. (2018) 'Designing convivial food systems in everyday life'. Paper presented at ServDes2018 - Service Design Proof of Concept, School of Design, Politecnuio di Milano, Available online https://ep.liu.se/ecp/150/086/ecp18150086.pdf [Accessed 15.3.2021].

Barad, K. (2012) 'Interview with Karen Barad: Matter feels, converses, suffers, desires, yearns and remembers'. In Dolphijn, R. and Van der Tuin, I. (eds), New Materialism: Interviews and Cartographies, pp. 44-70. Michigan: Open Humanities Press.

Barthel, S., Crumley, C., and Svedin, U. (2013) 'Bio-culturalrRefugia: Safeguarding diversity of practices for food security and biodiversity.' Global Environmental Change 23: 1142-1152.

Berry, W. (1993) Standing on Earth. Ipswich: Golgonooza Press.

Berry, T. (2006) Evening Thoughts: Reflecting on Earth as Sacred Community. San Francisco: Sierra.

Charlton, N. (2008) Understanding Gregory Bateson: Mind, beauty, and the sacred Earth. New York: SUNY series in Environmental Philosophy and Ethics.

Curtin, D. (1992) 'Recipes for values'. In Curtin, D. and Heldke, L. Bloomington (eds), Cooking, Eating, Thinking: Transformative Philosophies of Food. Indianapolis, IN: Indiana University Press. 
Dempster, B. (2000) 'Sympoietic and autopoietic systems: A new distinction for self- organizing systems', available online from http://www.isss.org/2000meet/papers/20133.pdf.

Fabre Lewin, M. (2012) 'Liberation and the art of embodiment'. In Hogan, S. (ed.), Revisiting Feminist Approaches to Art Therapy, pp. 15-124. London: Bergahn.

Fabre Lewin, M. (2019) Artful bodymind: Enlivening transformative research methodologies. PhD Manuscript, available online at www.touchstones.earth.

Fox, M. and Sheldrake, R. (1996) Natural Grace: Dialogues on Science and Spirituality. London: Doubleday.

Gablik, S. (1992) Connective aesthetics. American Art 1(2): 2-7.

Grimes, R. (2015) Ritual studies: Practicing the craft. Available online: https://humanitiesfutures.org/papers/ ritual-studies-practicing-the-craft/ [accessed July 18th 2019].

Haley, D. (2016) A question of values: Art, ecology and the natural order of things. In Demos, T. (ed.), Elemental: An Arts and Ecology Reader, pp. 41-62. Manchester: Gaia Project Press.

Haraway, D. (2015) Anthropocene, Capitalocene, Plantationocene, Chthulucene: Making Kin. Environmental Humanities 6: 159-165.

Haraway, D. (2016) Staying with the Trouble. London: Duke University Press.

Haraway, D. (2017) Symbiogenesis, sympoiesis, and art-science activisms for staying with the trouble. In Tsing, A., Swanson, H., Gan, E., and Busbandt, N. (eds) Arts of Living on a Damaged Planet. London: University of Minnesota Press, M35-M50.

Haley, D. (2016) A question of values: Art, ecology and the natural order of things. In: Demos T. J. (ed.) Elemental: An arts and ecology reader. Manchester: Gaia Project Press.

Ho, M. (2008) The Rainbow and the Worm: The Physics of Organisms. London: World Scientific Publishing.

Illich, I. (2001) Tools for Conviviality. London: Marion Boyars.

Laszlo, E. (1996) Manifesto on planetary consciousness. Paper adopted by the Club of Budapest on 26 October 2016. Available online: www.issuu.com/exopolitika/docs/the_manifesto_on_planetary_consciousness [accessed May 12th 2015].

Lemke, H. (2007) The extended art of eating: Joseph Beuys' unknown gastrosophy'. In SANSAI: An Environmental Journal for the Global Community, 2: 53-65.

Macy, J. (1991) World as Lover, World as Self. Berkeley: Parallax Press.

Mathews, F. (2003) For the Love of Matter: A Contemporary Pansychism. Albany: State University of New York Press.

Maturana, H. R. and Varela, F. (1980) Autopoiesis and Cognition: The Realization of the Living. Dordrecht, Holland: D. Reidel Publishing Company.

Menaken, R. (2020) 'Notice the rage; notice the silence' Online interview with Krista Tippett. Available online: https://onbeing.org/programs/resmaa-menakem-notice-the-rage-notice-the-silence/.

Merleau-Ponty, M. (1945) Cezanne's doubt. Available online: www.//faculty.uml.edu/rinnis/cezannedoubt.pdf [10 August 2016].

Puig de la Bellacasa, M. (2017) Matters of Care: Speculative Ethics in More Than Human Worlds. London: University of Minneapolis Press.

Roszak, T. (1977) Person/Planet: The Creative Disintegration of Industrial Society. Lincoln: i- Universe.

Ryan, K., Myers, N., and Jones, R. (eds) (2016) Rethinking Ethos: A Feminist Ecological Approach to Rhetoric. Carbondale: Southern Illinois Press.

Salami, M. Exousiance: A black feminist vision of power and nature. Available online: http://www.whatisemerging.com/opinions/exousiance-a-black-feminist-vision-of-power-and-nature-7c08ddb2-d336-4885add4-be8aca6a376e (accessed August 1st 2020).

Scientific American (1976) 'Future of Agriculture'. Volume 235 Issue 3.

Some, M. P. (1998) The Healing Wisdom of Africa: Finding Life Purpose through Nature, Ritual and Community. New York: Tarcher Putnam.

Steel, C. (2008) Hungry City: How Food Shapes Our Lives. New York: Random House.

Thomas, E. (2000) The Life of Buddha as Legend and History. New York: Dover Publications.

Tsing, A., Swanson, H., Gan, E. and Busbandt, N. (eds) (2017) Arts of Living on a Damaged Planet. London: University of Minnesota Press.

Turner, V. (1969) The Ritual Process: Structure and Anti-Structure. London: Transaction Publishers.

Turner, V. (1985) Liminality, Kabbalah, and the Media. London: Academic Press.

Van Gennep, A. (1960) The Rites of Passage. Chicago, IL: University of Chicago Press.

Weber, A. (2019) Enlivenment: Towards a Poetics for the Anthropocene. London: MIT Press.

Weiwei, I. (2020) Weiweisms. Available online at https://aiweiweihumanity.com/weiweisms/ [accessed May 3rd 2020]. 